\begin{tabular}{c|c|c|c|c|c|c}
\hline Days & 1 & 2 & 3 & 4 & 5 & 6 \\
\hline$\%$ & 20.5 & 27.9 & 27.2 & 25.8 & 25.0 & 24.5 \\
$\mathrm{~s}$ & 6.4 & 5.6 & 6.6 & 6.2 & 6.5 & 5.5 \\
\hline $\mathrm{s}_{s}$ & $>\mathrm{t}(2 \%)$ & $>\mathrm{t}(1 \%)$ & $>\mathrm{t}(5 \%)$ & $>\mathrm{t}(5 \%)$ & $>\mathrm{t}(5 \%)$ & $>\mathrm{t}(2 \%)$ \\
\hline
\end{tabular}

Radioactivities in blood streams were minimal, when labelled-RBC were injected into epidural tissues or, when hemolysed labelled-RBC into the cisterna magna.

\title{
23. Cerebral Angiography in Mentally Retarded Children and Some Trials of Neurosurgical Procedure for These Patients
}

\author{
Jiro Suzuki, Akira Takaku, Norio Harada and Shigeaki Kanayama \\ Division of Neurosurgery, Institute of Brain Diseases, \\ Tohoku University, School of Medicine
}

Cerebral angiographic examination was performed in a systematic manner on 108 cases of the mentally retarded children.

The extracranial portion of the internal carotid of most of mentally retarded children was longer than that of healthy ones. The carotid siphon showed the open type especially in the severely retarded cases. The media angle in most cases was longer than that of healthy ones. In $40 \%$ of the mentally retarded children the various pathological changes were observed on the carotid angiograms.

a) The abnormalities of the internal carotid arteries were observed as follows; Seven cases of sharp kink or tortuosity, 2 cases of localized narrowing and 2 cases of the irregularity of the wall of internal carotid artery were seen.

b) Many abnormalities of the intracranial main arteries were also found in the retarded children.

Four cases showed occlusion or stenosis of the anterior or middle cerebral arteries.

In 5 cases the main cerebral arteries were abnormally distensible. In 4 cases the course of the anterior cerebral artery showed the type of smooth winding arch resembling the running of the artery in the later stage in the fetal stage.

In 8 cases the straight deviations of the anterior cerebral arteries indicating the cerebral hemisphere were observed.

In 4 cases the abnormal runnings of the large arch of the anterior cerebral arteries were seen. 
c) Some abnormalities on the peripheral portion of the intracranial arteries were observed as follows;

Three cases of diffuse vascularization, 5 cases of localized vasculaization and 3 cases of small scattered groupings of vascularity were seen.

It was assumed that those abnormal vascularizations ensued from the birth trauma or from the inflammatory events.

On the base of these investigations of the carotid angiography, surgical treatments were tried on 5 cases with abnomalities of the arteries which might cause mental retardation. Some improvements of inteligence were see in 3 cases of above-mentioned 5 cases.

More cases of the mentally retarded children who may be indicated for the neurosurgical procedure would be found, if one would examine the cerebral angiography for them.

\title{
24. A Case of Teratoma Occupying the Left Hemisphere in a Young Infant
}

\author{
Masahiro Ogata and Yasuaki Yoshida \\ Neurosurgical Division of Kobe Municipal Central Hospital
}

This case was a young female infant who was born in a normal position and in a full term delivery. The birth weight was $3250 \mathrm{gm}$. The circumference of her head at that time was $33.5 \mathrm{~cm}$, but after birth the head enalrged gradually and its circumference became $50.5 \mathrm{~cm}$ at hospitalisation (aged 2 months). Immediately, ventriculo-atrial shunt was performed under a diagnosis of a simple hydrocephalus. The skull became a little smaller, but a short time after it became enlarged again. Consequently, the infant was suspected of having an intracreanial tumor by the pneumoventriculography. The tumor was a teratoma occupying the left hemisphere, and it was thought to arise from the left sphenoidal ridge, and it was extirpated totally by craniotomy. The tumor was $727 \mathrm{gm}$ in weight and contained multilocular cysts and solid part.

Histological examination revealed that the tumor contained that three germinal components: squamous stratified epithelium, immature neural tissue, striated and smooth muscles, adipose tissue, connective tissue, cartilage, digegstive tract mucosa etc. The tumor showed no malignancy in any part. 3 months after the operation, the infant died of purulent meningitis due to secondary infection of intracranial dead space. Autopsy could not be performed.

The favorite locations of the intracranial teratomas are on the midline, especially the pineal and pituitary regions are the sites of predilection, but they may 